\title{
An Exploration of Learning Art Activities in Children of Divorced Parents
}

\author{
Ju Chen \\ Associate Professor, Teacher Education Center Chaoyang University of Technology, Taiwan \\ Tzong-Ming Wey ${ }^{*}$ \\ Assistant Professor. Teacher Education Center, Chaoyang, University of Technology. Taiwan \\ Wan-Chi Hsu \\ Department of Early Childhood, Chaoyang University of Technology, Taiwan
}

\begin{abstract}
This study is aimed at exploring whether learning about art activities can help children of divorced parents in three aspects, namely self-concept, emotional expression, and linguistic expression. The researcher designed appropriate art activities for children of divorced parents based on their family backgrounds. There were nine art activities in total, including "self in the mirror", "painting with paint", and "pick-up and paste". From February to April in 2016, these art activities were conducted once a week for 40 minutes, led by the researcher. During these art activities, data were collected through observations and interviews and then coded and analyzed. To ensure the correctness of the analysis results, triangulation was applied for verification with three angles, the researcher's, the case subject's caretaker's (the grandmother's), and the case subject's custodian's (the father's). The research findings are summarized below: 1. In the aspect of family and self-concept, the art activities helped the children of divorced parents with their self-exploration and self-assertion. 2. In the aspect of emotional expression, the art activities offered the children of divorced parents more opportunities to express their feelings and gradually reveal their true emotions inside. 3. In the aspect of linguistic expresision, the art activities offered the children of divorced parents more opportunities for expression. The children were allowed to express their thoughts and ideas through drawing images and symbols. Lastly, based on the research findings, as references for children of divorced parents and related future studies.
\end{abstract}

Keywords: Art activity; Art therapy; Children of divorced parents.

(9) (1) CC BY: Creative Commons Attribution License 4.0

\section{Introduction}

Divorces of parents may lead to single-parent families, step-parent families, and grand-parent families. The issue of divorce and having a single parent has always been one of the main social issues in Taiwan. The influences on children and teenagers of single parents that come with this issue shall not be underestimated. The divorce of their parents must, in a way, impact children psychologically to a certain degree.

\section{Non-Linguistic Activities of Expressive Arts}

Art therapy is a clinical psychological therapy integrating expressive arts activities and psychological therapy. It is a professional therapy with projections of individual potential emotional conflicts, personality development, mental abilities, and hobbies based on art materials, mental images, art creation process, and subjects' feelings (Albert, 2010). The origin of art therapy can be traced back to cave drawings by prehistoric men (Albert, 2016). The first form of communication through human drawings is drawings on slates, rocks, or sculptures made of potter's clay, wood, or stones. People delivered a message, a hope, or an idea in a symbolic way through drawings. Prehistoric books were written in cuneiform characters, pictograph, and famous cave drawings (Anderson, 1994).

Multiple art materials are used for expressive arts therapy. Expressive arts therapy is a type of psychological therapy with therapists guiding their subjects in a safe and protected environment to express their internal thoughts and feelings through a non-linguistic expression form of symbolic creation so that the subjects can release their internal emotions and potentials to achieve the goal of self-healing (Elkins and Deaver, 2015). Compared with the traditional oral language-oriented therapy that is commonly applied, art therapy offers another option: An option with a non-linguistic way of communication and a safe and non-threatening space for expression, to help subjects to release their emotions and purify themselves, and to give them an opportunity for self-expression, selfcommunication, and self-growth (Gonzalez-Dolginko, 2008).

\section{Research Scope}

1. The research subject of this study is a four-year old girl living in New Taipei City. Her parents got divorced when she was 3 years old. She lived with her father after the divorce. Moreover, the usual caretaker of this girl was her grandmother.

2. The research content is based on the art activity the researcher designed according to the child's conditions, 
with the main purpose of exploring whether the child could express her own emotions through the art creation activity, helping her with her linguistic expression, and further helping her to get to know more about her self-concept.

3. During the research period, the research subject was not old enough to go to kindergarten. Thus, the activity was performed in the subject's house. First, the subject's caretaker and father were interviewed to learn more about the subject and to collect related information. The activity was performed once a day (with a 40-minute session), two days a week. The original plan was to do complete 9 sessions within 5 weeks. All the sessions were completed within 6 weeks.

\section{The Structure of Art Therapy}

For most people, expression through arts is not a common channel for communication. It is not easy for them to control this kind of expression or they may simply hide their feelings by not expressing them. In addition, they may somehow unconsciously and unexpectedly express the true feelings and emotions inside (Nelson, 2010). In a general consulting process, the main relationship is the relationship between the therapist and the subject. However, in an art therapy process, besides the one-on-one consulting relationship or group member relationship in group therapy, there is also the relationship between the subject and his art works as there are creation through materials and art works involved. With this additional relationship, there is a relationship triangle in art therapy, which is the "art creation therapist - subject" triangle.

\section{The Characteristics of Children's Drawing and the Stages of Drawing Development}

\subsection{The Characteristics of Children's Drawing}

Drawing is a psychological language, an integrated way for an individual to visually express his feelings and how he sees things based on his experiences through his own imagination and art activities. Children's drawing is usually one of the most direct channels for them to communicate their individual conscious or subconscious experiences (Liebmann, 1991). Drawing is also a way for children to convey what they realize. It is not necessary to worry about not being able to understand children's drawing. Children are like little architects. Through trial and error, they continuously build their cognitive structures of things. Each stroke is an important practice for them. Scribbling is an essential part of children's growing process, as well as a crucial factor influencing the development of their personalities, movements, and drawing (Fan, 1996).

Characteristics of drawing are different in different stages of development. The subject of this study was in her preschematic stage. The characters in her drawings were mostly presented as "tadpole-human figures" with a circle as the head, two smaller circles inside that circle as the eyes, and four lines outside the circle as limbs.

Children's drawings can reflect their real and unique selves. They are important for diagnoses and evaluations in art therapy activities (Potash and Sunderland, 2016). When provided with art materials, children can directly express their impressions on things through art expression without interference from others or external environments (Arteche and Murray, 2011). Various subtle physical and psychological changes of children can be found through careful observation of their drawings. For example, their drawings can show whether their emotion is peaceful, serene, or anxious, and whether their temperament is outgoing and happy or introvert and melancholy. Thus, this study allowed the child to express her thoughts about or views on things through drawing using art materials.

\section{Domestic and Foreign Studies Related to Art Therapy}

The range of applications of art therapy has become wider and wider. Barrett (2008) mentioned in her book that the art therapy promoted by Naumburg is often used in hospitals and clinical treatment institutions to help patients with mental illness. Naumburg's study (Cassidy, 2000) illustrated the changes in depression, ulcers, and alcoholism treatment of three female patients with emotional disorders after going through the art therapy. Images could facilitate the expression of internal conflicts in the form of symbols and thus speed up the treatment process.

The research subjects of Barrett (2008) were the children with mental retardation from a class for children of special needs in an elementary school. They were divided into two groups, the experimental group and the control group. The drawings of these children with emotional and behavioral problems related to flinch or resistance were analyzed using the qualitative analysis method to explore the concepts in these drawings. Moreover, the changes in mental images in the drawings and effects were compared between the two groups based on the draw-a-person (DAP) test results.

The research structure of this study is composed of four stages: preparation stage, development stage, research stage, and combined activity stage. The details of these stages are summarized below:

\section{Preparation Stage}

The main effort in the first stage, the preparation stage, is to discuss the research topic with the advisor. After the topic was set, the researcher began to collect and read related literature. On the other hand, the researcher also read the literature on drawing analyses and did some practices to make up for the lack of relevant experiences. 


\section{Development Stage}

The stage after the literature review is the development stage. This stage is about confirming the affairs related to the research case subject. Through the interview with the caretaker of the case subject, more information about the case subject's conditions was retrieved. The researcher also discussed with the advisor about the case subject's conditions to confirm the plan for the art activity to be performed later. The researcher also kept in touch with the caretaker to keep track of the case subject's conditions all the time in order to make corresponding changes.

\section{Research Stage}

During the research stage, the intervention of the art activity was delivered. Every time, after the activity was completed, the observations of the activity were recorded. Then the second round of the activity was compared with the first round. After that, the researcher discussed with the advisor about the child's conditions during the activity. The third round was then combined with the first two rounds to perform the activity. The resulted data were coded and collected for later management and analyses.

\section{Research Conclusions}

During the $9^{\text {th }}$ session, the subject was sick. As a result, she was not willing to express through images and symbols. Moreover, her oral expressions were not consistent during this session. However, in all the other sessions, the subject was willing to draw images and make oral expressions. During the last session, the contents of the subject's expressions were consistent. She was confident enough to say that she would help to take care of babies after growing up. This same idea was also expressed through her drawings.

During the whole research process, the case subject was not old enough to go to kindergarten and therefore was at home. In this environment with other people around, she might be influenced. A suitable space was required to perform the activity. Thankfully, her family was willing to help and made a space for the subject to participate in the art activity with the researcher. However, during the research period, because of several schedule conflicts with the family's outing plans, the schedule for the activity was changed. In addition, during the $9^{\text {th }}$ (the last) session, the subject suffered from gastroenteritis. She was sick and without vitality. After the activity, the researcher talked to the family and learned more about the subject's condition that day. Then the researcher discussed with the advisor and decided to combine the previous sessions into one complete activity for further observations. This study was able to contact the case subject's family of origin directly. The triangulation method from art therapy was applied with the main caretaker (the grandmother) and the custodian (the father), who were both interviewed, and the researcher who was leading the activity and observing the subject's behaviors and drawings. All the data obtained were crossreferenced for the purpose of getting to know the subject more.

\section{Reference}

Albert, R. (2010). Being both: An integrated model of art therapy and alternative art education. Art Therapy Journal of the American Art Therapy Association, 27(2): 90-95.

Albert, R. (2016). AATA's role in school-based prevention and intervention services. Art therapy today. American Art Therapy Association: Alexandria, VA.

Anderson, F. E. (1994). Art-centered education and therapy for children with disabilities. Charles C Thomas: Springfield, IL.

Arteche, A. and Murray, L. (2011). Maternal affective disorder and children's representation of their families. Journal of Child and Family Studies, 20(6): 822-32.

Barrett, T. F. (2008). Manic defenses against loneliness in adolescence. The Psychoanalytic Study of the Child, 63(1): 111-36.

Cassidy, J. (2000). Adult romantic attachments: A developmental perspective on individual differences. Review of General Psychology, 4(2): 111-31.

Elkins, D. E. and Deaver, S. P. (2015). American art therapy association, Inc. 2013 membership survey report. Art Therapy. Journal of the American Art Therapy Association, 32(2): 60-69.

Fan, Q. F. (1996). Psychological analysis and counseling of children's paintings - discussion on family dynamic painting. Psychology Press: Taipei, Taiwan.

Gonzalez-Dolginko, E. (2008). The secret lives of art therapists: An exploratory study about the nature of the work that art therapists do in schools (Unpublished doctoral dissertation). Hofstra University: Hempstead, NY.

Liebmann, M. (1991). Art therapy for groups: A hand book of themes, games and exercises. Routledge: London.

Nelson, C. L. (2010). Meeting the needs of urban students: Creative arts therapy in Jersey City Public Schools. . Art Therapy Journal of the American Art Therapy Association, 27(2): 62-68.

Potash, J. and Sunderland, L. (2016). Representing art therapy in the schools-NEA new business item D: Specialized instructional support personnel (SISP). Art Therapy Today. American Art Therapy Association: Alexandria, VA. 